\title{
CONEXÕES HISTÓRICAS ENTRE LINGUAGEM E JORNALISMO
}

\section{HISTORICAL CONNECTIONS BETWEEN LANGUAGE AND JOURNALISM}

\author{
Carlos Borges Junior \\ Professor da Universidade do Tocantins \\ Doutorando em Linguística Aplicada pela Universidade Federal de Santa Catarina \\ Membro do grupo de pesquisas Língua, Discurso e Interação - cadastrado CNPq \\ E-mail: borges-junior@hotmail.com
}

\section{RESUMO}

Este artigo aponta conexões históricas que permitem discutir o jornalismo enquanto ato singular de língua(gem). O estudo registra o percurso da fala à escrita para constituição social da linguagem e em seguida passa a discutir algumas conexões históricas entre linguagem e jornalismo para problematizar o jornalismo enquanto ato de linguagem. A discussão bibliográfica permite localizar momentos de intersecção entre os campos desde o registro de informações nas paredes das cavernas, na Grécia pré-socrática e na retórica; Idade Média e Renascimento; Iluminismo; Tempos Modernos e Contemporâneos. Todos alicerçados a partir do recorte linguagem e jornalismo. Entre os fundamentos teóricos destacam-se Cagliari (2002), Bakhtin (2011), Gomes (2000), Sousa (2008), Lage (2005), entre outros.

Palavras-chave: História. Jornalismo. Linguagem.

\begin{abstract}
This article points on historical connections that allow to discuss journalism as a singular act of language (s). The study records the path from the speech to the writing for a social constitution of language and then goes on to discuss some historical connections between language and journalism and then to problematize journalism as a language act. The discussion of the bibliography gives you the chance to find moments of intersection between the fields that range from the registration of information on cave walls, in the pre-Socratic and rhetoric Greece, to the Modern Era and Contemporary world, passing through Middle Ages, Renaissance and Enlightenment. All these registration are grounded from the cut language and journalism. Among the theoretical foundations stand out Cagliari (2002), Bakhtin (2011), Gomes (2000), Sousa (2008), Lage (2005), among others.
\end{abstract}

Keywords: History. Journalism. Language. 


\section{INTRODUÇÃO}

O papel contínuo da comunicação social como fator condicionante não aparece em nenhum lugar de maneira mais clara e completa do que na linguagem. A palavra é o fenômeno ideológico por excelência. A realidade toda da palavra é absorvida por sua função de signo. A palavra não comporta nada que não esteja ligado a essa função, nada que não tenha sido gerado por ela. A palavra é o modo mais puro e sensivel de relação social.

(BAKHTIN, 2004, p. 36)

A assertiva de Mayra Rodrigues Gomes (2000, p. 19), na qual assegura que "o jornalismo é ele próprio um fato de língua" toma o fazer jornalístico implicado na questão da linguagem. Isto significa dizer que a linguagem ${ }^{1}$ torna-se matéria-prima, substância elementar para representação do mundo. Ela é apresentada de forma singular em cada acontecimento noticioso, produzido pela atividade jornalística de constituição da informação. Nesse sentido, para que se possa evidenciar o Jornalismo como Ato de Língua, faz-se necessário um olhar sobre alguns pressupostos da Linguística que teorizam o campo da lingua(gem $)^{2}$ e relacioná-los a instituição histórica do jornalístico como ato de linguagem.

\section{GÊNESES: LINGUAGEM E JORNALISMO}

“É, com efeito, na língua e pela língua que o indivíduo e sociedade se determinam mutuamente" (PRETI, 1982, p. 2). A relação que se desencadeia entre ambas não é de mera casualidade, pois "desde que nascemos um mundo de signos linguísticos nos cerca e suas inúmeras possibilidades comunicativas começam a se tornar reais a partir do momento em que aprendemos a formular nossas mensagens" (PRETI, 1982, p. 1). Assim, a língua desempenha um papel preponderante tanto em sua forma oral, quanto em seu código escrito, e, na atividade jornalística, de maneira geral, o jornalista utiliza-se dos dois recursos que ela oferece:

A língua é o suporte de uma dinâmica social, que compreende, não só as relações diárias entre os membros da comunidade, como também uma atividade intelectual, que vai desde o fluxo informativo dos meios de comunicação de massa, até a vida cultural, científica ou literária. (...) É através dela que a realidade se transforma em signos pela associação de significantes sonoros e significados arbitrários, com os quais se processa a comunicação (PRETI, 1982, p. 2).

O aspecto oral, a representação escrita da lingua(gem) e a esfera social em que a linguagem se organiza alicerçam a prática discursiva que constitui o fenômeno jornalístico para a produção de notícia. O homem que, na história, inicialmente, começou a produzir e articular sons, 
os aprimorou a ponto de torná-los linguagem. A linguagem, a princípio, era apenas sons, gestualidades, contextos e práticas sociais. Devido às práticas sociais, a linguagem já nasce fazendo referência aos objetos, coisas e ações; também fará referência a muitos outros contextos necessários a significação do mundo, antes que seja representada em sua forma escrita.

No nascimento da linguagem, os sons dão origem à fala e ela passa a fazer referência aos seres do mundo real. Vai assumindo o caráter de representação do mundo social. Entretanto, o percurso dos sons produzidos até a linguagem como uma convenção arbitrária que nomeia o universo dos significados de forma escrita não acontece repentinamente. O homem percebe na linguagem certa capacidade que o difere dos outros animais. Ele é um ser-falante, que apreende a si e ao mundo na/pela/através da linguagem. Assim, o aparato da fala já faz do homem um extraordinário ser e o torna ainda mais significante quando é capaz de verter em símbolos gráficos o que antes eram apenas sons de comunicação. O homem cria, arbitrariamente, um código escrito, que será convencionado substitutivo da fala sem obrigatoriedade da interação face a face para se comunicar e construir significados. A escrita se torna uma grande tecnologia desenvolvida por este ser racional para o desenvolvimento da humanidade. Na escrita, o homem formula um conjunto de símbolos gráficos que registram o pensamento e constrói sentidos, antes somente idealizado através da própria fala e da interação face a face.

A história da escrita, segundo Luiz Carlos Cagliari, vista em seu conjunto sem seguir uma linha de evolução cronológica, pode ser caracterizada em três fases distintas: a fase pictórica, a ideográfica e a alfabética. A primeira "se distingue pela escrita através de desenhos ou pictogramas"; a segunda "pela escrita através de desenhos especiais chamados ideogramas" e a última "se caracteriza pelo uso de letras" (CAGLIARI, 2002, p. 106-109).

Estas três fases retomam, pela associação da linguagem, o pensamento de Luiz Beltrão acerca de ser o jornalismo uma das atividades humanas mais antigas, pois de acordo com o autor, "quando o homem das cavernas vigiava a aproximação de animais ferozes, ou descobria um curso d'água piscoso ou um trecho da floresta em que abundava a caça; quando reunia o seu clã para informá-lo e convencê-lo da necessidade de emigrar ou de enfrentar o inimigo que avizinhava" fazia jornalismo em pelo menos três aspectos: informando, orientando e entretendo (BELTRÃO, 2006, p. 13). Se observarmos por este ângulo, quando o homem descobre que pode utilizar-se da linguagem para informar, orientar e entreter vale-se dela para registrar nas paredes das cavernas e do tempo as informações para os que estavam por vir. Temos aí o princípio da informação pelo aspecto pictórico da linguagem (no registro das imagens), mas o desenvolvimento da linguagem, no que concerne à fala e depois à escrita, será imprescindível para prolongar no tempo a representação do mundo, da comunicação das ideias, do conhecimento e da informação. 
Nesta gênese, Jorge Pedro Sousa (2008) também vai fundamentar certo fenômeno pré-jornalístico no mundo antigo com as pinturas rupestres como exemplos do registro de informações deixados pelos antepassados e também a invenção e contribuição da literatura, retórica e historiografia, com atenção ao surgimento e aprimoramento da escrita para o berço do Jornalismo se estruturar. Alguns pressupostos e referências para uma origem do jornalismo enquanto transmissão da informação pela linguagem.

\subsection{A RETÓRICA, O JORNALISMO E A LINGUAGEM}

É pela linguagem, no que primeiramente se relacionou à fala depois à escrita, que se registram os interesses individualizados e sociais de um falante em relação a outro. Contudo, a existência da alteridade no instante da comunicação já dá à linguagem um princípio social a que ela está imbrincada - vai de uma necessidade pessoal ainda limitada a um evento social: do particular ao público em sua rede de práticas e eventos:

$\mathrm{Na}$ língua como instituição social nos organizamos enquanto pacto, sempre levando em conta o estatuto desse pacto/língua que nos precede e em relação ao qual não temos escolha. Somos constituídos na linguagem como sujeitos singulares de um só golpe (GOMES, 2000, p. 15-16).

Ser constituído na linguagem implica operar no campo da fala, da oratória, da retórica e em outro processo, também poder participar do espaço da escrita, que se associa ao âmbito da argumentação materializada por um código. Ao constituir-se pelos domínios da linguagem, o jornalismo utiliza-se da retórica como técnica argumentativa capaz de expressar o pensamento, operando o discurso como habilidade de expressão em relação aos interlocutores a ponto de estabelecer a controvérsia através dos atos singulares de fala (enunciados).

No período conhecido como Grécia pré-socrática diz-se que a mobilização ideológica era exercida pelos aedos homéricos, cantores que discursavam e envolviam as plateias com melodia e música, assegurando a "verdade da mensagem", isto é, o argumento, visto que se entendia que o bom orador era o que regulava a participação da plateia no relato e na ação (LAGE, 2005). Tinham como artífice o ato de interromper as apresentações que realizavam em momentos cruciais, criando certa expectativa no público, estratégia usada para assegurar a audiência do dia seguinte e a atenção do interlocutor (LAGE, 2005).

A retórica foi, entre os filósofos gregos, o ato público de grande debate das ideias. Foi o pilar da argumentação por um longo período histórico. A argumentação sempre teve por objetivo a adesão dos espíritos, pressupondo a existência de um contato intelectual que resultava no conflito 
entre a forma de conceber o mundo e as coisas através do pensamento (PERELMAN e OLBRECHTS-TYTECA, 1996). É deste princípio que se vale o jornalista, no intuito de reconstruir o campo da retórica e convencimento e causar o debate na construção do fenômeno noticioso, de modo que o discurso argumentativo torne o acontecimento mais convincente e verossímil. Para isso, faz-se indispensável à argumentação estabelecer a controvérsia, pois ao contrário de isolar os conjuntos da retórica, pretende-se confrontá-lo a ponto de que a recepção o discuta, visto que o presente social dura poucos dias, mas os comentários gerados pela controvérsia duram semanas (GOMIS, 1991).

Por outro lado, a representação do pensamento escrito torna-se base para que opere a dedução. Esta se dará a partir da concepção de materialização da linguagem em um sistema, isto é, pela linguagem que assume sua representação gráfico-simbólica em uma sociedade que evolui da fala para a escrita.

No percurso fala-escrita, a palavra escrita passa a ser a própria representação do mundo simbólica e/ou ideológica. Ao jornalista convém reconstituir o campo da retórica por meio da palavra mediada no ato de fala. Este ato atualiza a noção de presente na linguagem jornalística a fim de alcançar a diversidade de auditórios: o universal (formado por todos os homens, que podem pensar igual ou diferente do posicionamento lançado na sua argumentação), o interlocutor (a quem o jornalista se dirige - seu público, do qual deve-se resguardar da ideia de que o interlocutor sempre terá a mesma convicção resoluta que o enunciador, pois nos estudos de mídia também há o instante da negação por parte do receptor para a negociação argumentativa, às vezes até a negação da ideia do enunciador) e o próprio sujeito (ele próprio, o jornalista, que delibera sobre suas razões e seus atos, construindo sua própria convicção da argumentação). Nestes espaços que constituem os atos de fala, não basta ser apenas persuasivo ou convincente, mas valer-se de eloquência precisa, verossímil e objetiva para construção das notícias (PERELMAN e OLBRECHTS-TYTECA, 1996).

\subsection{DISPUTAS PELA PALAVRA: INSTÂNCIAS DE PODER}

No contexto em que a palavra se torna veículo de poder e dominação, de acordo com Maurizzio Gnerre (1991), à linguagem se associa diretamente um jogo de poder, principalmente à linguagem escrita, espaço este, que somente os que dominam a produção textual-discursiva para fins comunicativos com certas especificidades materiais - a escrita - podem ocupar. Gnerre ressalta que "as pessoas falam para serem 'ouvidas', às vezes para serem respeitadas e também para exercer uma influência no ambiente em que realizam os atos linguísticos" (1991, p. 5). A 
atividade jornalística, pelo uso da palavra, reafirma o pacto social de acordo com uma legalidade reconhecida no contexto social. Por isso investiga, denuncia e provoca o embate de discursos. Através da palavra consignada, o jornalismo desestabiliza certos sistemas sociais quando os apresenta em seus momentos de crise. Torna-se um fato de língua ao cumprir "o ato pelo qual delegamos (ou somos forçados a delegar) a palavra a ele enquanto representante a falar por nós, a fazer justiça por nós" (GOMES, 2000, p.16).

$\mathrm{Na}$ instância do valor a que a palavra se associa, "escrever nunca foi e nunca vai ser a mesma coisa que falar" (GNERRE, 1991, p. 8), entretanto, o poder da retórica também é veículo de dominação e, ao longo da história, estes mecanismos ideológicos de dominação e poderio, os quais deram origem ao Estado pela organização da sociedade, aconteceram por meio da palavra e da força que ela exercia/exerce, já que a preservação da unidade dos grupos humanos em sociedade sempre precisou de uma voz de comando, chefes, conselhos etc., para tomada de decisões. Eles eram/são a representação da palavra e do poder que dela emanava/emana. Nas civilizações antigas, aonde o poder do Estado estava diretamente relacionado à autoridade dos caciques e sacerdotes que negociavam espaços e privilégios, manipuladores do espaço simbólico e ideológico do pensamento, já se registrava a influência da linguagem como forma de domínio.

Quando os sacerdotes, reis, chefes, entre outros representantes, concebem que é a linguagem o grande pilar do conhecimento, da informação, da crítica, ideologia, etc., resguardam o povo do acesso a ela, encaram-na como um bem tão valioso cuja posse e domínio deve se restringir a uns poucos que regem a sociedade. A linguagem que provém dos núcleos que gerem os espaços sociais é tida como legítima e autorizada pela razão divina, enquanto que a que emana do povo é desvalorizada e encarada como profana. Assim, os espaços sociais de acesso à erudição pela linguagem são estreitados, sendo o conhecimento e a informação que o povo recebe, objetos interpretados segundo as convicções dos que compõem as esferas de poder, artífice que limita o campo de visão dos indivíduos, privando-os da liberdade de expressão.

Este cenário compõe a realidade da Idade Média, tempo histórico em que a Europa entra em um período de trevas e obscurantismo do conhecimento racional, conquistas educativas, sociais, políticas e culturais - época de profundo retrocesso da informação. Tempo em que a Igreja Católica monopoliza a maneira de pensar e agir de toda uma sociedade, instituindo-se como a detentora do poder soberano do conhecimento, resumindo: mil anos de poderio eclesiástico aonde a informação e o conhecimento eram malefícios a serem combatidos com mãos de ferro, já que as verdades já haviam sido previamente definidas - fixadas pelos reguladores da sociedade que estavam no poder. Assim, a troca de informações teve de valer-se da oralidade para resistir ao cerceamento imposto pela censura ao escrito. 
Nesta época, todo o poder cultural esteve centralizado nas decisões da Igreja, porém, quando ela se vê na impossibilidade de controlar os progressos do conhecimento somado à incapacidade de gerir seus territórios, passa a delegar autoridade aos leigos, disseminando socialmente o ofício da copiagem manuscrita, até então gerenciada pela própria instituição religiosa. O papel, nesse período, já não era problema, mas somente poucos ainda escreviam, o que fez com que a atividade cultural se difundisse pela oralidade, inicialmente. O que preocupava o Estado e a Igreja era o risco de que mensagens contrárias à regulação do poder fossem disseminadas em meio à sociedade.

O tempo que tem por referência as Actas Diurnas ${ }^{6}$ como sendo o primeiro exemplo seguro do jornalismo na história da humanidade, seguida das folhas noticiosas volantes, cartas e crônicas medievais, antes, de publicação sempre regulada pelo pulso forte ora do Estado, ora da Igreja, vai ver surgir, com o Renascimento, o florescer de uma nova perspectiva para toda a Europa através do disseminar de novas ideias.

\title{
3 O RENASCIMENTO E A INVENÇÃO DA IMPRENSA
}

Com o advento do Renascimento, as mudanças aconteceram em todas as esferas sociais, mas é no campo do conhecimento seu ponto fulcral. A difusão de livros e outras publicações apoiadas no espetacular invento de Gutenberg - o sistema tipográfico - que imprimia livros e escritos, antes somente manuscritos, fez disseminar uma nova cultura na Europa, compreendida entre os finais do século XIV e meados do século XVI.

\begin{abstract}
A intensificação do comércio subjacente ao período renascentista gerava riqueza, suscitava o desejo de lucro e impulsionava a vontade de investir. Assistia-se, por outro lado, à intensificação da circulação de informações e ideias, prefigurando a liberdade de expressão das sociedades livres e democráticas contemporâneas e possibilitando a construção de novos conhecimentos e a difusão de novos artefactos e técnicas. Além disso, a cultura da renascentista orientava-se, crescentemente, para o escrito, embora faltasse assegurar a possibilidade de transmitir fielmente a mesma mensagem a um vasto número de pessoas e a grandes distâncias. A conjuntura do Renascimento contribuía, assim, para o aparecimento de vários inventos [e inventores, tal como] Johann Gensfleich zum Gutenberg [que criou o sistema tipográfico e] deu à humanidade um futuro melhor, abrindo condições para o aparecimento e para o sucesso da indústria jornalística (SOUSA, 2008, p. 31-32).
\end{abstract}

Neste tempo histórico, a cultura escrita começa a adquirir importância superior à cultura oral: ocorria a difusão da informação impressa. "A invenção do livro e sobretudo da imprensa são grandes marcos da História da humanidade, depois é claro da própria invenção da escrita" (CAGLIARI, 2002, p. 112). Entretanto, da oralidade, o jornalismo detêm algumas lições: “1) 
importância da comunicação oral e da imagem criada (rádio e tv); 2) a dificuldade de adequar o discurso ao público pretendido, 3) visto a diferença entre a classe média a que os jornalistas pertencem em relação ao restante da população" (LAGE, 2005, p. 27). Foi, sobretudo, no aspecto escrito que o invento de Gutenberg fez emergir uma nova configuração cultural nos primeiros anos da Renascença.

\begin{abstract}
A invenção de Gutenberg investiu de dignidade a figura do impressor-editor à escala dos ofícios burgueses, ao erigir-se em símbolo de um espírito urbano, carregado de individualismo, racionalista, de valores concretos, sem sentimentos de culpa ante o lucro econômico e em ascensão progressiva dentro da sociedade da época. Ao mesmo tempo contribuiu para racionalizar a cultura europeia e desviá-la rebeldemente da autoridade escolástica, da teocracia e do magister dixit, em favor da liberdade de pensamento e de expressão, do inconformismo e da tolerância (GARRIDO apud SOUSA, 2008, p. 32).
\end{abstract}

Neste período oportuno surgem as folhas volantes, antepassados de nossos jornais atuais, com temáticas variadas: expansões marítimas, naufrágios, assuntos religiosos, notícias da Corte, batalhas, acontecimentos gerais e etc.

A invenção de Gutenberg abriu espaço, deu condições para o aparecimento e o sucesso da indústria jornalística. As publicações que se seguiram estavam relacionadas a iniciativas comerciais de uma burguesia que logo priorizou sua educação, alfabetizando seus núcleos e as variadas profissões que poderiam beneficiá-la, o que lhe garantiu poderio nesta virada estratégica da história do conhecimento e sua difusão. O aprimoramento da prensa viabiliza à burguesia emergente a participação nos assuntos do Estado e a difusão de seus próprios interesses.

Em uma Europa monárquica e absolutista de direito divino, fragmentada pelas divisões cíveis, ameaças de revoluções e reformas entre Católicos e Protestantes, tinha-se formado o espaço público para receptividade de notícias, bem como matéria-prima para informação, constructos constituídos com a relevância da linguagem no espaço público. Surgem desse contexto os primeiros jornais eminentemente jornalísticos denominados gazetas, nome relacionado ao custo da produção derivado da moeda veneziana, que era pago pela leitura pública das folhas impressas. As gazetas tinham periodicidade definida e frequente, além de atitude informativa (SOUSA, 2008). Ela evolui das folhas volantes que circularam seguido ao Renascimento, foram consideradas como um amadurecimento dos editores que logo perceberam que a publicação das mesmas consistia num bom negócio (SOUSA, 2008). Assim, "o acto de informar tal como é praticado pelos jornalistas, não pertencem às relações individuais, de pessoa a pessoa. É um ato social que se desenrola num espaço público, num território que é também o do político" (CORNU, 1999, p. 132), de modo que a história da imprensa começa com a descoberta da impressão, que garante ao conhecimento, à informação e ao jornalismo a possibilidade de, pela palavra consignada, fazer parte do espaço público. 
A evolução [da história da imprensa] inscreve-se num fundo histórico que lhe determinará profundamente as orientações. A afirmação da sua liberdade passa pela emergência do individualismo, pela restauração da liberdade religiosa, pelo reconhecimento da liberdade de opinião, pelos progressos da ideia de tolerância, por novas reflexões sobre o Estado e a sociedade, pelo aparecimento de uma esfera pública, entre a esfera privada dos indivíduos e a esfera do poder, por experiências individuais e colectivas, por acontecimentos sociais e políticos (CORNU, 1999, p. 133).

Da invenção e revolução provocada pela imprensa até a emergência do ciberjornalismo há ainda um vasto período a percorrer, porém o que impulsiona a atividade jornalística a ultrapassar os liames do tempo e manter-se ainda presente nele, consiste talvez no aspecto de que o Jornalismo seja ele próprio um fato de língua, que, por ser caracterizado dessa maneira, na movência do tempo, conseguiu resguardar em seu fenômeno noticioso associado à linguagem, a carga significativa de sua ação na mesma proporção a que Benjamin se refere ao falar da história da arte: “cuando Benjamin reivindica un punto de vista 'ahistórico' [que] no lo hace para negar la historicidad como tal, sino para dejar de lado el punto de vista de uma historia abstracta y apelar, de rebote, a un modelo de "historicidad específica"” (DIDI-HUBERMAN, s/d, p. 122). Isto significa que o jornalismo possui uma linguagem específica em cada momento histórico devido às várias configurações sociais que o envolve. Torna-se novo com a linguagem do seu tempo. Esta especificidade linguística a que se refere na citação condiz ao fato de ser o jornalismo a própria linguagem que se atualiza na singularidade do fenômeno noticioso, já que "a ação do jornalismo caminha do universal para o singular e o texto jornalístico faria o caminho de volta, tendo como fundamental a particularização e por horizonte o universal", somado às questões de linguagem (GENRO FILHO, 1987, p. 195).

\subsection{DO UNIVERSAL AO PARTICULAR COMO ATO DE LINGUAGEM JORNALÍSTICA}

Em associações entre o campo da linguagem e do jornalismo dir-se-á que o particular é a forma de a linguagem se apresentar para significar o conteúdo da notícia. Esse evento específico constitui o que Bakhtin (2011, p. 261) denomina de enunciado. Contudo, são os modos específicos de uso da linguagem dentro da esfera jornalística que constitui a natureza da linguagem do jornalismo.

A linguagem, em forma de enunciados noticiosos, rompe as barreiras do tempo e se atualiza em sua forma de fazer jornalismo para cada época. Também é pela linguagem que o campo jornalístico registra e identifica suas teorias e bases epistemológicas de estudo: desde a primeira tese sobre o Jornalismo apresentada em 1690, na Universidade de Leipzig - Alemanha, 
por Tobias Peucer, que se observa quão atual é investigação sobre o fazer noticioso com a perspectiva do singular, confirmando a periodistika como primeiro e antigo ramo da Comunicação e Informação, mas não deixando de perceber que desde 1690 a maioria dos temas que discutimos hoje no campo do jornalismo já era problematizado: perpassando pela questão da autoria, noticiabilidade, verdade e credibilidade, o que deve ou não ser publicado devido a seleção dos fatos, bem como a forma e o estilo dos periódicos.

O texto de Peucer parte da origem do termo novellae, entendido como "nova comunicação" e o relaciona ao instante em que os monges o empregam como "notícia", ressaltando o momento em que a palavra passa a despertar a curiosidade do público para o conhecimento das coisas novas. A partir da descoberta da palavra como fonte de informação, curiosidade etc., Peucer (2004) destaca os gauleses e belgas como aperfeiçoadores deste gênero de escrita peculiar ao jornalismo ainda em surgimento, que avança no trabalho dos mercúrios franco-belgas. A princípio, escreviam-se fatos históricos acontecidos em qualquer lugar que fosse. Aos poucos, esses atos de narrar foram se tornando mais populares, pois a curiosa novidade dos impressos seduzia pela linguagem a uns e deixavam outros desconfiados (PEUCER, 2004). Mas o fato é que é a linguagem o artífice que seduz e garante a audiência da palavra, deixando no ar a expectativa do que é o acontecimento e do que o segue - "algo parecido com a estratégia dos folhetins do século XIX" (LAGE, 2005, p.20), ou com a deflagração de um escândalo midiatizado em tempos atuais. Neste, há o acompanhamento da audiência de todos os acontecimentos até o lance final.

No passado ou no presente, a linguagem atualiza o jornalismo à época em que registra os fatos do dia. Cristina Ponte (2005), no livro Para entender as notícias: linhas de análise do discurso jornalístico, perpassa por várias teorias que discorrem sobre a história do jornalismo e a produção de notícias como atividade social. Focaliza sua discussão na viragem linguística e sociológica encarando linguagem e sociedade como organismos dinâmicos e interativos. Do campo da linguagem, a autora ressalta que o jornalista deve escrever numa lógica comunicacional, sem exageros estilísticos, o que denota sempre pensar no público a quem escreve, sobretudo se se pensar acerca do que concebe por viragem linguística, ideia que integra uma contribuição da filosofia pragmática da linguagem, passando de uma análise formal do texto para uma análise de sua realização em contexto, isto é, sai-se da estrutura para o campo social, do texto para o discurso, do enunciado para a enunciação, para a esfera social da linguagem, dialogicamente fundamentada nas perspectivas de Bakhtin. 


\subsection{PERSPECTIVAS E MUDANÇAS NO ESPAÇO CULTURAL ILUMINISTA}

No século XVIII, a linguagem também proporciona o espaço cultural ${ }^{7}$ de discussão, pois, segundo Sousa (2008), graças à perspectiva Iluminista, a opinião pública provoca debates dos vários saberes em meio social, sobretudo nos cafés e salões europeus, onde emerge uma imprensa "de partido", noticiosa, de elite - uma imprensa da difusão do conhecimento. Com a revolução industrial, os avanços tecnológicos dão ao jornalismo uma produção em maior escala, o preço dos exemplares vendidos ao público é reduzido e a linguagem torna-se mais clara e acessível devido ao caráter comercial e publicitário dos jornais.

Nessas publicações, a linguagem passa a promover o que é de "interesse humano": educação para todos, combate ao desemprego (sem generalização de sexo e camada social), abolição da escravatura, trabalho infantil, sufrágio universal, entre outros temas que ainda estão representados nas páginas atuais e nos noticiários de quaisquer veículos da informação nos dias de hoje. Já o século $\mathrm{XIX}^{8}$ vê a implantação de cursos de jornalismo. A linguagem, ao passo que registra as notícias, vai fundamentar a "ciência jornalística" nas universidades alemãs, suíças, francesas e americanas.

Segundo Sousa (2008), a palavra consignada no rádio e, posteriormente, na televisão alicerçam as novidades do século XX. O jornalismo vai se utilizar desses meios como suporte para a informação. Com o tempo, o radiojornalismo se converte ao que hoje intitula-se radiojornal, com notícias sendo divulgadas "de hora em hora", com transmissões desportivas, culturais e científicas em programas de entrevistas, debates e reportagens. Já o telejornalismo referencia-se ao documentário cinematográfico, ao rádio jornal e às notícias e reportagens radiofônicas. Nesta época, o telejornal se caracteriza pelos jornalistas que se sucedem na leitura das notícias, depois, elege-se um âncora-apresentador que dá unidade, direciona e organiza a série de notícias a serem repassadas ao interlocutor-telespectador e culmina em um modelo de telejornal que surge com a CNN, onde o telejornalismo mostra, em tempo real e ao vivo, o que está a acontecer em "todos" os pontos do planeta onde há a presença de jornalistas para noticiar. A linguagem é o próprio presente noticiável, é o presente singular do agora (SOUSA, 2008).

Os fins do século XX e início do século XXI marcam um período muito desafiador para o campo. No centro está uma forte discussão entre objetividade/subjetividade acerca da linguagem jornalística, sobretudo da objetividade como método para apurar os fatos, convergindo para zonas de construções epistemólogicas relacionadas à informatização das redações, onde se desenvolveu um espaço cultural para que a internet se tornasse ferramenta no trabalho com a informação e linguagem (SOUSA, 2008). 
A internet deu e dá margem para que o trabalho do webjornalismo, espaço da informação alimentado com textos, sons e imagens, renove a forma do fazer e receber as informações. A atividade jornalística no espaço digital permite a interação de usuários com as notícias disponibilizadas na rede mundial, quebrando os oligopólios da informação pela força da globalização, onde as fronteiras entre o local e o global se fragmentam (SOUSA, 2008). Mas neste espaço cibernético, a retórica do hipertexto ainda tem "entre sus finalidades dar a las formas de expressión, escritas o habladas, la eficacia suficiente para deleitar, conmover, persuadir y, em definitiva, atraer a los auditórios públicos o a una generalidad de lectores" (CASASÚS apud LÒPEZ, 2003, p. 387). Ela atrai os leitores estabelecendo uma nova retórica através da linguagem, que também se faz nova pela invenção de uma escrita que constitui o hipertexto, a forma que se atualiza na maneira de se apresentar e significar a linguagem em uso.

\section{CONSIDERAÇÕES FINAIS}

O percurso realizado na história do jornalismo a partir do eixo linguagem mostra como o trabalho com a palavra tem contribuído para solidificar ao longo do tempo o interesse público pela informação. Em cada tópico do texto, tentou-se articular o passado e o presente no trabalho jornalístico com a linguagem. Desde os registros nas paredes das cavernas até as mais sofisticadas plataformas de notícias digitais, a linguagem que noticia os acontecimentos e informa quanto aos fatos relevantes do cotidiano se constitui no elemento que consegue ultrapassar as barreiras do tempo, atualizando não só o jornalismo, mas a própria linguagem em suas práticas sociais de produção e publicação da informação.

Em todos os registros jornalísticos há uma particularidade, uma singularidade jornalística atualizada em linguagem. Esta atualização configura-se em um ato de língua - o enunciado, materializado nas reportagens, notícias, manchetes, entre outros gêneros jornalísticos. O jornalismo é um ato de língua porque se constitui em linguagem, e como toda linguagem, possui o caráter de tornar-se novo para registrar os acontecimentos, eventos e fatos de seu tempo, tornando-os sempre atuais. A linguagem é matéria, forma, conteúdo, símbolo e desafio diário ao jornalismo na produção da informação. Ela é o elemento utilizado seja para fundamentar teoricamente o campo e contextualizá-lo ou para construir o espaço público na sua natureza de informar. Nestas ou em outras perspectivas, é com a linguagem que o fazer jornalístico ultrapassa as fronteiras do tempo e sobrevive no seio social como ato de língua: como enunciado. 


\section{NOTAS}

$1 \mathrm{Na}$ estrutura da linguagem, todas as noções substanciais formam um sistema inabalável, constituído de pares indissolúveis e solitários: o reconhecimento e a compreensão, a cognição e a troca, o diálogo e o monólogo, sejam eles enunciados ou internos, a interlocução entre o destinador e o destinatário, todo signo provido de significação e toda significação associada ao signo, a identidade e a variabilidade, o universal e o particular, o social e o individual, a coesão e a divisibilidade, a enunciação e o enunciado (BAKHTIN, 2004, p. 10)

2 A grafia da palavra língua(gem) utilizada neste artigo segue a mesma relação a que se refere o linguista John Lyons quando expressa estar "ciente da ambiguidade do termo 'language' no inglês, que significa possuir uma língua e ser dotado de linguagem, dois significados possíveis, que em português são dois vocábulos distintos: 'língua' e 'linguagem' (LYONS, 1987, p. 15).

3 Estes aparecem em inscrições antigas, mas podem ser vistos de maneira mais elaborada nos cantos Ojibwa da América do Norte, na escrita asteca (veja o catecismo asteca, por exemplo) e mais recentemente nas histórias em quadrinhos. (CAGLIARI, 2002, p. 106)

4 As escritas ideográficas mais importantes são a egípcia (também chamada de hieroglífica), a mesopotâmica (suméria), as escritas da região do mar Egeu (por exemplo, a cretense) e a chinesa (de onde provém a escrita japonesa). (CAGLIARI, 2002, p. 108)

5 Os sistemas mais importantes são o semítico, o indiano e o greco-latino. Deste último provém o nosso alfabeto (latino) e o cirílico (grego), que originou o atual alfabeto russo. (CAGLIARI, 2002, p. 109)

${ }^{6}$ As Actas Diurnas já apresentam, na antiguidade, a configuração da atividade de produção jornalística da modernidade. Para a elaboração delas havia certo corpo de redatores (escravos alfabetizados), que coletavam informações no palácio e no senado para publicar, ainda que houvesse um controle do que deveria ser publicado (SOUSA, 2008). As actas eram impressas em tábuas de madeira ou argamassa de cera e tinha conteúdo diverso - traziam informações sobre feitos populares, disputas esportivas, execuções e condenações além de fofocas e boatos sobre figuras "ilustres" que emergiam socialmente (SOUSA, 2008). Eram fixadas em murais localizados em prédios públicos e/ou distribuídas aos comerciantes e generais, o que garantia a circulação de informações naquele espaço público (SOUSA, 2008).

7 Há outros fatores, acontecimentos na esfera pública, que auxiliam o jornalismo a se manter em meio social, não apenas a linguagem. Esta por sua vez apenas registra e põe em pauta outros acontecimentos ligados à atividade jornalística: o desenvolvimento da riqueza, o aumento da produção devido a colonização, a consolidação de Estados, as novas descobertas científicas, a Independência dos Estados Unidos, a Revolução Francesa, o domínio da doutrina liberal sobre o antigo regime da aristocracia, entre outros (SOUSA, 2008).

8 Neste século surgem as primeiras organizações profissionais dos jornalistas; são implantadas as agências de notícias e o fazer da profissão utiliza-se do telégrafo e fotojornalismo para a troca de informações. A imprensa se desenvolve a ponto de ser alçada como "quarto poder", visto ser porta-voz da opinião pública. (SOUSA, 2008).

\section{REFERÊNCIAS}

BAKHTIN, Mikhail. Estética da criação verbal. São Paulo: Editora WMF Martins Fontes, 2011.

BELTRÃO, Luiz. Teoria e Prática do Jornalismo. Adamantina: FAI/Cátedra UNESCO Metodista de Comunicação para o Desenvolvimento Regional / Edições Omnia, 2006. 
CAGLIARI, Luiz Carlos. Alfabetização \& Linguística. São Paulo: Editora Scipione, 2002.

CORNU, Daniel. Memória de uma Liberdade. In CORNU, Daniel. Jornalismo e verdade: para uma ética da informação. Lisboa: Instituto Piaget, 1999.

DIDI-HUBERMAN, Georges. Ante el Tiempo: Historia del arte y anacronismo de las imágenes. Buenos Aires: Adriana Hidalgo Editora, s/d.

GNERRE, Maurizzio. Linguagem, Escrita e Poder. São Paulo: Martins Fontes:1991.

GOMES, Mayra Rodrigues. Jornalismo e Ciências da Linguagem. São Paulo: Hacker Editores/Edusp, 2000.

GOMIS, Lorenzo. Teoria del Periodismo: cómo se forma el presente. Barcelona: Paidós, 1991.

LAGE, Nilson. Os estilos e seu tempo. In LAGE, Nilson. Teoria e técnica do texto jornalístico. Rio de Janeiro: Elsevier, 2005.

LÓPES, Xosé. Retórica del hipertexto periodístico. In: DÍAS NOCI, Javier y SALAVERRÍA ALIAGA, Ramón (Coords.). Manual de Redacción Ciberperiodística. Barcelona: Ariel, 2003.

LYONS, John. Lingua(gem) e Linguística: Uma Introdução. Rio de Janeiro: Editora Guanabara, 1987.

PERELMAN, Chaim e OLBRECHTS-TYTECA, Lucie. Tratado da Argumentação: a nova retórica. São Paulo: Martins Fontes, 1996.

PEUCER, Tobias. Os relatos Jornalísticos. In: Estudos em Jornalismo e Mídia VI. No 2. Florianópolis: Pósjor UFSC/Insular, 2004.

PONTE, Cristina. Para entender as notícias: linhas de análise do discurso jornalístico. Florianópolis: Insular, 2005.

PRETI, Dino. Sociolinguística: Os níveis da fala. 4a Edição. São Paulo: Companhia Editora Nacional, 1982.

SOUSA, Jorge Pedro. Uma história breve do Jornalismo no Ocidente. In: SOUSA, Jorge Pedro (Org.). Jornalismo: história, teoria e metodologia. Porto: UFP, 2008. 